\title{
Des perspectives plus risquées en Asie
}

Dernière mise à jour : 1 mars 2017

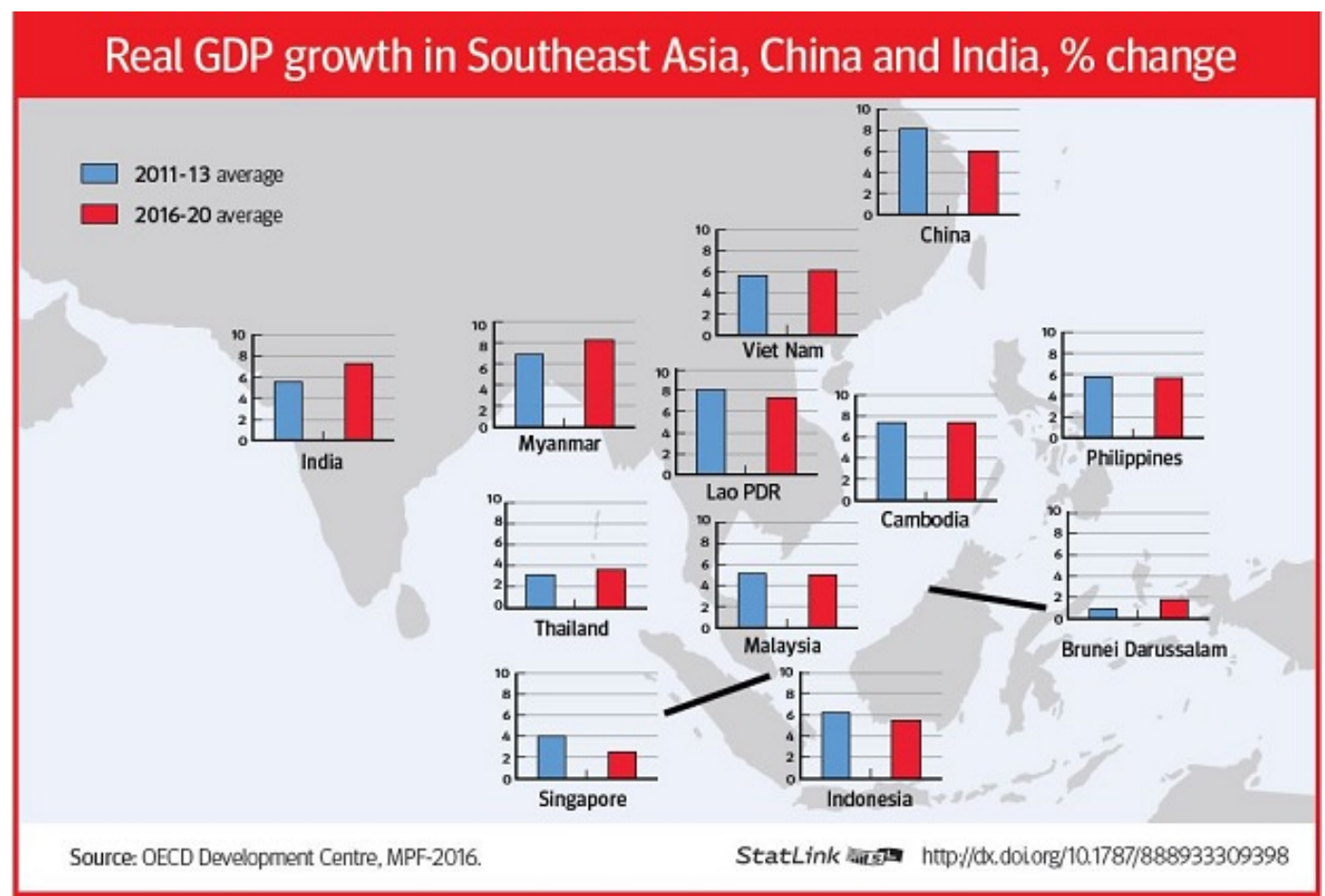

La croissance du PIB réel a ralenti dans la plupart des économies émergentes d'Asie en 2014 et est restée modeste en 2015, selon la publication Economic Outlook for Southeast Asia, China and India 2016. En fait, la plupart des pays de la région ont enregistré une croissance plus lente en 2015 qu'en 2014, sauf le Brunéi Darussalam, la Thailande, le Viet Nam et l'Inde. La Chine et la région de l'ASEAN ont connu leur plus faible croissance depuis le début de la crise financière mondiale.

Néanmoins, la croissance devrait s'accélérer dans l'essentiel de la région, tandis que l'activité redémarre dans les économies avancées, que la baisse des cours du pétrole stimule la consommation et que la croissance de l'investissement se redresse, selon le rapport, qui souligne que les paramètres économiques fondamentaux sont « globalement favorables ». La baisse de l'inflation sousjacente a permis à la plupart des pays de mener une politique monétaire plus expansionniste. Les soldes des transactions courantes et du compte de capital se sont légèrement dégradés, mais les positions extérieures globales restent saines. 
Les marchés de capitaux de la région ont été relativement résilients face au recul des entrées nettes de capitaux et aux incertitudes liées aux perspectives de resserrement monétaire aux États-Unis et de ralentissement de la croissance en Chine. Ces incertitudes font peser des risques à la baisse sur ces perspectives, sachant que des risques supplémentaires découlent des ajustements concernant l'envolée des prix immobiliers et la croissance du crédit dans divers pays.

Pour en savoir plus, consultez http://oe.cd/M5 